\title{
New technologies in the prevention and control of healthcare-associated infection
}

\author{
H Humphreys \\ Professor and Consultant Microbiologist, Department of Clinical Microbiology, Royal College of Surgeons in Ireland, and Department of \\ Microbiology, Beaumont Hospital, Dublin, Ireland
}

This review is based on a presentation by Professor Humphreys at the RCPE Healthcare-Associated Infection Symposium on 2 February 2010.

ABSTRACT The increased interest in healthcare-associated infection (HCAl) among the public, patients and politicians has led to the development of potential new approaches to its prevention by industrial concerns and others. Such developments include better methods of assessing hospital hygiene, enhanced decontamination of the healthcare environment, biosynthetic tissue alternatives, antibiotic-impregnated medical devices and information technology that can help improve professional practice. Although promising, many of these have not been adequately evaluated in the clinical setting, highlighting the need for greater collaboration between industry and infection prevention and control practitioners to maximise the benefit of new products and to complement conventional approaches to $\mathrm{HCAl}$ prevention such as education, professional practice and the provision of better facilities.

KEYWORDS Healthcare-associated infection, hospital hygiene, information technology, medical devices

DECLARATION OF INTERESTS Professor Humphreys has received research funding or support from Pfizer, Steris Corporation, 3M, Inov8 Science and Cepheid in the past three years. He has also received lecture or consultancy fees from 3M, Novartis and Astellas.
Correspondence to H Humphreys, Department of Clinical Microbiology, RCSI Education and Research Centre, Beaumont Hospital, PO Box 9063 Dublin 9, Ireland

tel. +353 I 8093708/37/0

e-mail hhumphreys@rcsi.ie

\section{BACKGROUND}

The prevention and control of healthcare-associated infection (HCAl) has reached the top of the political and healthcare agenda because of its contribution to patient morbidity and mortality, the significant healthcare costs that accrue from these infections and because of the dissatisfaction of some patients and their families with their care, especially in acute hospitals. In a study of more than 75,000 patients in the UK and the Republic of Ireland, 5-10\% of patients in acute hospitals had an $\mathrm{HCAl}$, which was associated with increasing age, male gender and the presence of an invasive device at the time of the survey or in the preceding seven days. ${ }^{1,2}$ A proportion of HCAl may be inevitable, particularly in severely ill patients with significant underlying pathology. However, there is increasing evidence that when all evidence-based preventative measures are implemented as part of professional practice, for some HCAls such as ventilator-associated pneumonia (VAP) the rate can approach zero, ${ }^{3}$ thus making a major contribution to patient care. Therefore reductions in $\mathrm{HCAl}$ are now seen as an index of improvements in the quality and safety of patient care.

The increasing interest in HCAl among the public, many healthcare professionals (other than those already directly involved) and politicians, together with its greater profile in the media, has meant that there is considerable interest within industry and the commercial sector in developing and applying innovative approaches to preventing or controlling HCAl. Conventional measures include the education of healthcare professionals and patients on simple measures, for example: hand hygiene; good professional practice such as compliance with recommendations on intravascular catheter care, patient isolation or cohorting; better surveillance to determine what changes may be taking place in the prevalence of certain HCAls or to detect outbreaks quicker; better facilities such as greater space between patients in hospitals and in other healthcare facilities; and improvements in hospital environmental decontamination. While some new technologies have potential, others do not appear to add significantly to what is already available or have not been adequately scientifically assessed. The inadequate assessment of new approaches is often because these have been developed by relatively small companies who do not have the facilities or resources to undertake large clinical trials which might conclusively prove whether or not a new approach is required.

Certain lines of investigation in the development of new products have been advocated or promoted recently. Some of these are reviewed here, excluding developments in rapid diagnostics, which have the capacity to prevent infection by earlier detection. 


\section{ENVIRONMENTAL CLEANLINESS}

A major debate that has oscillated back and forth across the Atlantic is the necessity for disinfection compared with detergents only as part of routine hospital cleaning. This issue is still largely unresolved. Furthermore, new technologies such as hydrogen peroxide and the use of copper or plasma are being proposed as alternatives, or in addition, to the use of detergents and surface disinfectants.

Even before considering new approaches to environmental decontamination, there needs to be agreement about how best to routinely assess hygiene. Visual inspection is crude and does not determine the presence or absence of important microbial pathogens such as methicillinresistant Staphylococcus aureus (MRSA) or Clostridium difficile. Increasingly, microbial assessment is being advocated to augment mere visual inspection. ${ }^{4}$

Hospital decontamination is usually carried out by cleaning operatives, often on low pay and on short-term contracts, and motivation with feedback is important for these and all other groups of healthcare workers. Carling and colleagues in Boston have developed and used a simple fluorescent tracking system to determine whether surfaces in hospitals have been adequately decontaminated. Without significant financial investment but with appropriate feedback on the quality and standard of hygiene, the use of this simple technology resulted in a significant improvement in hygiene levels. ${ }^{5}$

Another approach is the use of adenosine triphosphate (ATP) bioluminescence, which assesses the presence of biological material such as protein. Adenosine triphosphate readings do not correlate with visual assessment of cleanliness but decline after cleaning with parallel reductions in aerobic colony and MRSA counts. ${ }^{6}$ As with a fluorescent tracking system they offer the benefit of a rapid result compared with culture, but an improved assessment of cleanliness that includes the rapid detection of the presence or absence of marker organisms such as MRSA is required.

The design of the environment to be decontaminated is crucial in optimising cleaning, and more consideration needs to be given to the layout of the healthcare facility. Computers and computer keyboards are frequently touched on a hospital ward and are not straightforward to clean because of their shape and the need to avoid water that will interfere with electrical components. A multidisciplinary group in the UK has looked at how computer keyboards can be decontaminated more effectively and concluded that the preferred keyboard should have a flat profile, a cleaning alarm and a siliconcoded surface, as this is most likely to achieve and maintain low bacterial counts. ${ }^{7}$
Other approaches to improve surface decontamination include the use of microfibre cloths and mops, and copper. A study carried out in Birmingham found that commonly touched items containing copper, such as door handles and toilet seats, had $90-100 \%$ lower bacterial counts than their control equivalents. ${ }^{8}$ Microfibre cloths are recommended by some as they may be superior at decontaminating uneven surfaces with crevices at the microscopic level. These cloths have been combined with a novel copper-based biocide, resulting in a reduction in bacterial counts with a residual effect after the cleaning process, due to the copper. ${ }^{9}$

Most approaches to decontamination reduce but do not completely eradicate the microbes present. However, sterilising (i.e. the removal of all microbes, including bacterial spores) horizontal surfaces and the air in the vicinity of patients offers exciting possibilities in significantly improving cleanliness and potentially reducing infection. Ultraviolet light (UV) has germicidal activity, but there have always been concerns about its safety, hence design and installation are critical. When a UV unit is installed high enough in a room or a unit, the side effects such as conjunctivitis and skin erythema can be avoided. Ultraviolet light technology has been developed in recent years to counteract bioterrorism, ${ }^{10}$ but this technology has not been widely used in the healthcare sector.

An alternative approach to surface and air sterilisation is the use of hydrogen peroxide (HP), a recognised sterilant, in the form of a gas or mist. However, patients and staff need to be evacuated due to the potential toxicity of this gas during exposure. An in-vitro study has shown that HP can eradicate $6-7 \log _{10}$ colonyforming units of most vegetative bacteria and spores within 90 minutes." Similarly, HP has been shown to be effective in significantly reducing the number of positive MRSA samples taken during the terminal cleaning of single rooms or cohort areas, after patients with MRSA have been discharged. ${ }^{12}$ While many hospitals have used HP to control an outbreak, and some are using it to augment routine cleaning, a full evaluation is required to assess its longer-term impact on HCAl prevention.

A potentially less toxic approach is the use of thermal plasma and other variations in plasma technology. This approach appears to be particularly promising for the decontamination of surfaces or equipment with biofilm, as plasma can disinfect surfaces in less than 120 seconds. ${ }^{13}$ However, at this stage it is not clear how such an approach would be used cost-effectively in the healthcare sector; it needs to be evaluated further.

\section{SYNTHETIC MATERIALS AND ANTIBIOTIC- IMPREGNATED DEVICES}

Recent developments in bioengineering have resulted in the development of synthetic tissues to mimic those not available or to replace those that are inappropriate. In 
particular, there is a need for alternatives to bone (Figure I). Following multiple trauma, large tumours or destructive infection arising from osteomyelitis when the stability of the skeleton can be compromised, there is a need for alternatives as bone grafting is insufficient where there are large defects. Mechanical stability and a porous structure to facilitate cellular metabolic activity with the diffusion of the necessary chemicals and cytokines are required. ${ }^{14}$ Where the use of such material facilitates the more extensive removal of necrotic or potentially infected tissue, this will assist in the treatment of pre-existing infection, even if the long-term consequences remain to be assessed. Similarly, a number of alternatives using tissue-engineered skin replacements have been investigated. ${ }^{15}$ These developments have the potential to provide alternatives to infected tissues or structures and, in the delivery of antimicrobial compounds, to either prevent or treat infection.

There has been much interest from industry in the development and evaluation of a number of antibiotic or heavy metal-impregnated catheters or devices to minimise the acquisition of infection, either during device insertion or subsequently. However, it is unclear if these devices should be used routinely or as an adjunct to routine infection prevention measures, such as in particular highrisk patients, because of their cost. A recent meta-analysis of 34 randomised clinical trials concluded that chlorhexidine-silver-sulphadiazine and minocylinerifampicin central venous catheters have a role, if all other efforts have been used, to reduce the infection rate. ${ }^{16}$ Many units use such catheters in high-risk patients but not routinely, and a cost appraisal needs to be carried out to also determine whether the upfront costs of their use in the clinical area (e.g. the intensive care unit, ICU) is accompanied by downstream savings such as earlier discharge from hospital and reduced requirement for antibiotics.

A less expensive approach to preventing intravascular catheter infections is to apply disinfectant to the insertion site more effectively. A multi-centre trial in France showed that the application of chlorhexidine, a commonly used skin disinfectant, in the form of a sponge, resulted in reduced catheter-related infections and bloodstream infection (associated with a relatively high mortality in ICU), even when the dressings were changed less frequently, i.e. every seven days compared with the usual schedule of every three. ${ }^{17}$

Ventilator-associated pneumonia is a significant cause of morbidity and mortality in ICU patients. Conventional approaches to VAP prevention include reducing the duration of ventilation and intubation, where possible, closed suctioning and caring for the patient in the semirecumbent position. Nonetheless, many patients develop VAP the longer they remain ventilated in the ICU. A silver-coated endotracheal tube has been shown to

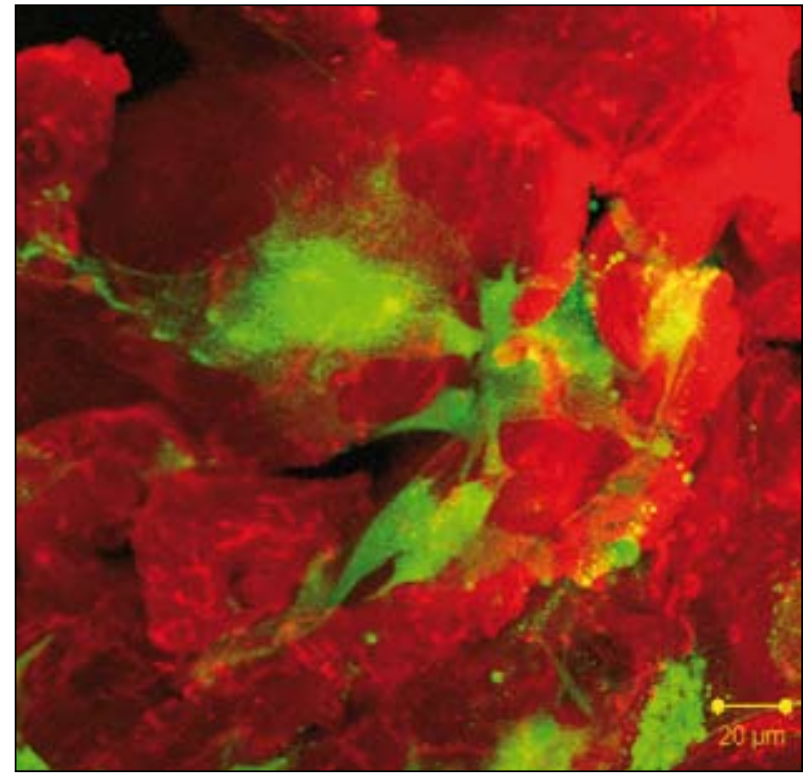

FIGURE I Confocal microscopy of osteoblasts (green) found embedded within a novel, porous collagen-glycosaminoglycan scaffold (red) designed for use in orthopaedics. (Courtesy of Professor Fergal O'Brien, Royal College of Surgeons in Ireland.)

reduce the prevalence of VAP; where pneumonia did occur, the use of silver-coated tubes led to a delayed occurrence. ${ }^{18}$ An economic evaluation has suggested that the use of such tubes may be cost-effective, even allowing for the increased cost of the catheter as this is offset by the significant costs of managing a patient with VAP. ${ }^{19}$

\section{INFORMATION TECHNOLOGY}

Better information and particularly more effective feedback can improve professional practice. Most of the healthcare developments in information technology relate to better and faster access to information and data, such as laboratory results available online. However, in the sphere of HCAl prevention and control, a number of technologies are now available that can monitor and record compliance with hand hygiene recommendations. Some of these simply count the number of times individuals decontaminate their hands, but body sensors are now available to monitor whether individuals decontaminate their hands appropriately and if aseptic technique was used when inserting an intravascular device. However, these largely remain to be fully evaluated.

Whether hand hygiene occurs when it should (e.g. before and after patient contact) is important, but there also needs to be more focus on how effective it is. A system that monitors compliance with the six components of hand hygiene (e.g. the decontamination of the palms, thumbs, etc.) has been developed. By assessing visual images captured on a video camera, the system can provide feedback to healthcare workers on whether this has been correctly carried out. ${ }^{20}$ This has the potential to be a useful educational tool as part of ongoing hand hygiene education. 
Healthcare bundles are evidence-based measures which, when introduced for all patients, have the potential to significantly reduce the rate of $\mathrm{HCAl}$ to the minimum. In a US study, average compliance with a bundle to prevent VAP was only $30 \%$, but following the use of an electronic dashboard that reminded ICU practitioners when and what to do, compliance increased to $89 \%$, with a decrease in VAP rates. ${ }^{21}$ Further developments in this area can help improve personal behaviour and professional practice, but healthcare workers will have to get used to surveillance of professional practice, such as the video-recording of hand hygiene, to improve compliance and to possibly reassure patients and the public.

\section{CONCLUSIONS}

There are interesting and exciting potential technologies emerging that may impact on the prevention and control of HCAI. Some of these represent direct interventions in patient care, such as antibiotic-impregnated devices, while others try to influence human behaviour, such as videos and body sensors, to improve compliance with best practice (Table I). However, these new technologies come at a price, and it is not clear what additional contribution they can make to routine measures.

\section{REFERENCES}

I Smyth ET, Mcllvenny G, Enstone JE et al. Four country healthcareassociated infection prevalence survey 2006: overview of the results. J Hosp Infect 2008; 69:230-48. doi:I0.1016/j.jhin.2008.04.020

2 Humphreys $\mathrm{H}$, Newcombe RG, Enstone J et al. Four country healthcare associated infection prevalence survey 2006: risk factor analysis.J Hosp Infect 2008; 69:249-57. doi:10.1016/j.jhin.2008.04.02I

3 Tolentino-DelosReyes AF, Ruppert SD, Shiao SY. Evidence-based practice: use of the ventilator bundle to prevent ventilatorassociated pneumonia. Am J Crit Care 2007; 16:20-7.

4 Dancer SJ. How do we assess hospital cleaning? A proposal for microbiological standards for surface hygiene in hospitals. J Hosp Infect 2004; 56: 10-15. doi:10.1016/j.jhin.2003.09.017

5 Carling PC, Parry MM, Rupp ME et al. Improving cleaning of the environment surrounding patients in 36 acute care hospitals. Infect Control Hosp Epidemiol 2008; 29:1035-40. doi: 10.1086/59/940

6 Sherlock O, O'Connell N, Creamer E et al. Is it really clean? An evaluation of the efficacy of four methods for determining hospital cleanliness.J Hosp Infect 2009; 72:140-6. doi:10.1016/j.jhin.2009.02.013

7 Wilson AP, Ostro P, Magnussen M et al. Laboratory and in-use assessment of methicilin-resistant Staphylococcus aureus contamination of ergonomic computer keyboards for ward use. Am J Infect Control 2008; 36:e 19-25. doi:10.1016/j.ajic.2008.09.001

8 Casey AL, Adams D, Karpanen TJ et al. Role of copper in reducing hospital environment contamination.J Hosp Infect 2010; 74: 72-7. doi:10.1016/j.jhin.2009.08.018

9 Hamilton D, Foster A, Ballantyne L et al. Performance of ultramicrofibre cleaning technology with or without addition of a novel copper-based biocide. J Hosp Infect 2010; 74:62-71. doi:10.1016/j.jhin.2009.08.006

10 Brickner PW,Vincent RL, First M et al.The application of ultraviolet germicidal irradiation to control transmission of airborne disease: bioterrorism countermeasure. Public Health Rep 2003; | I8:99-I I 4.

II Otter JA, French GL. Survival of nosocomial bacteria and spores on surfaces and inactivation by hydrogen peroxide vapor. J Clin Microbiol 2009; 47:205-7. doi:I0.I I28/JCM.02004-08
TABLE I New technologies to help prevent and control healthcare-associated infection

\begin{tabular}{|l|l|l|}
\hline Technology & Potential impact & Ref. \\
\hline \multirow{4}{*}{ Hygiene } & Better methods to assess cleanliness & 5,6 \\
\cline { 2 - 3 } & Design, e.g. computer surfaces & 7 \\
\cline { 2 - 3 } & $\begin{array}{l}\text { Cleaning, e.g. role of copper, } \\
\text { hydrogen peroxide, plasma }\end{array}$ & $8-13$ \\
\hline \multirow{2}{*}{$\begin{array}{l}\text { Antibiotic- } \\
\text { impregnated } \\
\text { invasive devices }\end{array}$} & Intravascular catheter & $16-17$ \\
\cline { 2 - 3 } $\begin{array}{l}\text { Information } \\
\text { technology }\end{array}$ & Endotracheal tubes & $18-19$ \\
\cline { 2 - 3 } & Screensavers & 20 \\
\hline
\end{tabular}

There is a need for greater collaboration between infection prevention and control practitioners, and industry to influence which technologies are developed and how they are evaluated. More field trials are required to confirm their potential when introduced into regular practice.While the future may see exciting developments, traditional approaches to prevention and control will probably still remain important, including hand hygiene, environmental decontamination, education and surveillance. Furthermore, not all developments need to be expensive or inaccessible, as 'simple may be best'.

12 French GL, Otter JA, Shannon KP et al. Tackling contamination of the hospital environment by methicillin-resistant Staphylococcus aureus (MRSA): a comparison between conventional terminal cleaning and hydrogen peroxide vapour decontamination.J Hosp Infect 2009; 57:3I-7. doi:10.1016/j.jhin.2004.03.006

13 Joshi SG, Paff M, Friedman G et al. Control of methicillin-resistant Staphylococcus aureus in planktonic form and biofilms: a biocidal efficacy study of nonthermal dielectric-barrier discharge plasma. Am J Infect Control 2010; 38:293-301. doi:I0.1016/j.ajic.2009.1I.002

I4 Al-Munajjed AA, Plunkett NA, Gleeson JP et al. Development of a biomimetic collagen-hydroxyapatite scaffold for bone tissue engineering using a SBF immersion technique.J Biomed Mater Res B Appl Biomater 2009; 90:584-91. doi:10.1002/jbm.b.31320

15 Priya SG, Jungvid $H$, Kumar $A$. Skin tissue engineering for tissue repair and regeneration. Tissue Eng B Rev 2008; 14:105-18. doi:10.1089/teb.2007.0318

16 Casey AL, Mermel LA, Nightingale P et al. Antimicrobial central venous catheters in adults: a systematic review and meta-analysis. Lancet Infect Dis 2008; 8:763-76. doi:10.1016/SI473-3099(08)70280-9

17 Timsit JF, Schwebel C, Bouadma L et al. Chlorhexidine-impregnated sponges and less frequent dressing changes for prevention of catheter-related infections in critically ill adults: a randomized controlled trial. JAMA 2009; 30I:1231-4I. doi:10.1001/jama.2009.376

18 Kollef $M H$, Afessa B, Anzueto $A$ et al. Silver-coated endotracheal tubes and incidence of ventilator-associated pneumonia: the NASCENT randomized trial.JAMA 2008; 300:805-13. doi:10.1001/jama.300.7.805

19 Shorr AF, Zilberberg MD, Kollef M. Cost-effectiveness analysis of a silver-coated endotracheal tube to reduce the incidence of ventilator-associated pneumonia. Infect Control Hosp Epidemiol 2009; 30:759-63. doi:10.1086/599005

20 Johnson L, Kavanagh P, Lacey $\mathrm{G}$ et al. An evaluation on the use of $a$ video system to improve the quality of hand hygiene. Atlanta: Fifth Decennial Conference in Healthcare-associated Infection; 2010.

2I Zaydfudim V, Dossett LA, Starmer JM et al. Implementation of a real-time compliance dashboard to help reduce SICU ventilatorassociated pneumonia with the ventilator bundle. Arch Surg 2009; 144:656-62. doi:10.1001/archsurg.2009.1I7 